a series of years, may be found useful in considering whether it is likely to prove a suitable health-resort in particular cases.

Ambulance Work: Questions and Answers upon "First Aid to the Injured." By J. W. Martin, M.D., and J. Martin. Pp. 47. London: Baillière and Co.-This little book has been compiled by the authors, not with a view to supersede, but to supplement, Shepherd's "First Aid to the Injured." The form of question and answer may probably be found an advantrgeous method of conveying instruction, and the cautions given against the pupil supposing that by having attended a course of ambulance lectures he has become qualified to take the place of the physician or surgeon are judicious. We are afraid, however, that some of the answers, especially in the anatomico-physiological portion, are beyond the general grasp of many of those for whom the book is intended. Nor are we quite satisfied with all the practical portion. For instance: "Q. If a child has swallowed a small coin, a bean, or other small, hard body, what might you do with success?-A. Hold the little patient up by the heels, inverting him." There might be considerable risk attending the carrying out of this process of inversion sinder such circumstances, unless performed by competent hands.

Dictionary of National Biography. Edited by LESLIE STrephen. Vol. VII. London: Smith, Elder, and Co.-The seventh volume of the Dictionary of National Biography, which has just been published, extends from "Brown" to "Burthogge," and its contents, in accuracy and literary polish, fully equal those of the preceding volumes. The favourable opinion which we expressed in our last notice of this publication has not been in any way diminished, and we congratulate Mr. Leslie Stephen on the manner in which he is performing his necessarily responsible task.

John Leech's Pictures of Life and Character from the collection of "Mr. Punch." London: Bradbury, Agnew, and Co.-We have received the first and second parts of this work, which is now being published in monthly instalments. It is well got up, considering the lowness of the price at which it is offered, and when completed will contain nearly 4000 sketches by the great master of English caricature, illustrating every section of social life from 1842 to 1864. John Leech's sketches are so familiar that it is unnecessary to describe them, and to everyone who does not possess a complete and handy copy of them we can advise the purchase of the collection which forms the subject of this notice.

Medical Annual, 1886. London: Kimpton.-The proprietors of this Annual have devoted several pages of the contents to a summary of the recent advances made in medicine and surgery, which will be found useful by members of the profession. The remainder of the volume is occupied with the subjects which formed the contents of the Annual for 1885 , and affords a useful source for reference apon many questions of interest to medical men.

Presentations.-On the 22nd ult., on the occasion of their annual dinner, the members of the West Kent Medico-Chirurgical Society presented Dr. Prior Purvis, of Blackheath, with a drawing-room clock and two vases braring the following inscription:- "Presented to Prior Purvis, M.D. Lond., by the members of the West Kent Medico-Chirurgical Society, in recognition of his valuable services as treasurer extending over a period of thirty years." Mr. D. A. Fraser, M.R.C.S., L.S.A., has also been presented with a clock by the inhabitants of Burnham, as a mark of their approval of the manner in which he has discharged the duties of medical officer of health to that town.

Royal Medical Benefolent College, Epsom.Founder's Day at this institution was celebrated on the 6th inst., when a large gathering of the friends and old pupils of the College attended to witness the distribution of prizes.

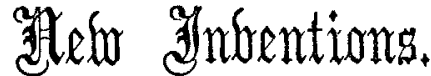

\section{A NEW LITHOTRITE.}

Ir has occurred to me, during the operation of lithotrity, that having with much patience seized a fragment of stone, I have again lost it in the attempt to lock the instrument, the morsel being of such size that the threads of the screw would not bite. An inspection of most old lithotrites will show that this must be no uncommon accident, as it will be seen that the edges of the male screw are burred from the force used to make it lock; and although theoretically it would appear impossible to remedy this defect, as a fresh catch would be necessary at every point of the screw, practically such perfection is needless, and the instrument (which has been ably made from my design by Messrs. Down Brothers of St. Thomas's-street) answers sufficiently well. Its novelty consists in two locks, so set that whenever the crests of the female screw of the first impinge directly on the crests of the male screw, the second lock can be brought into play by

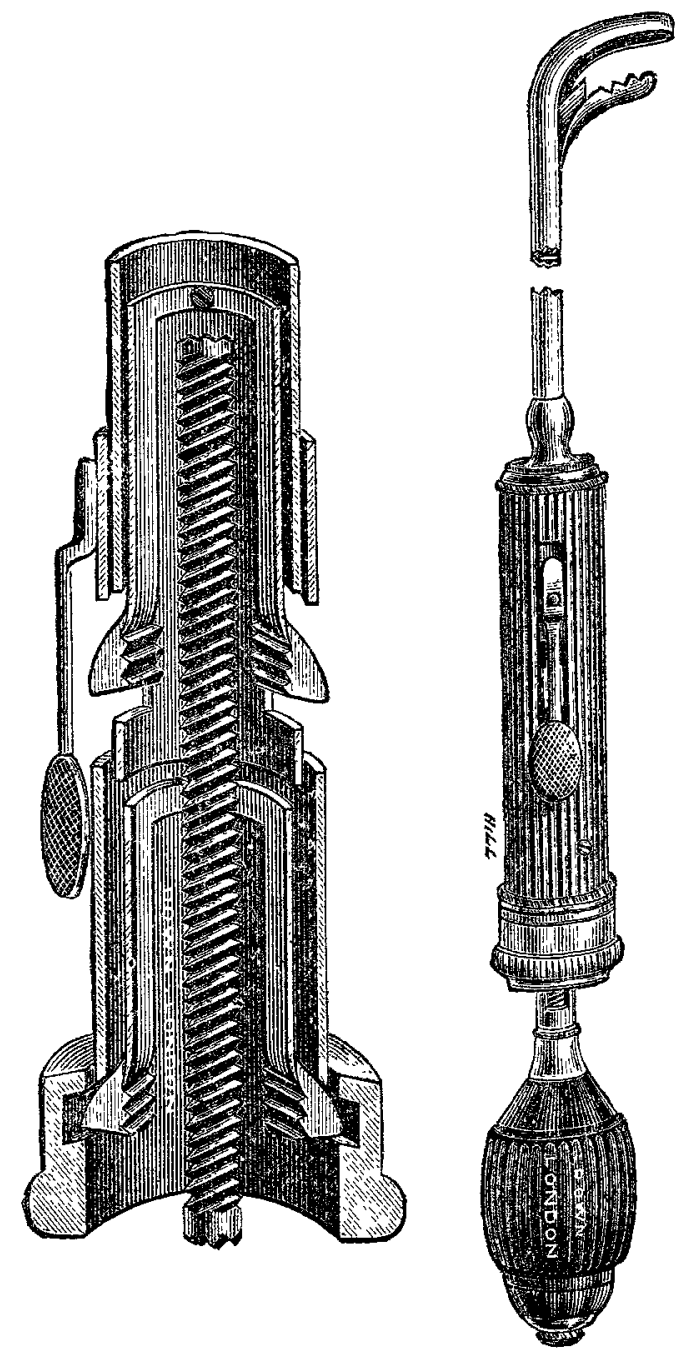

moving up the catch with the thumb without altering the position of the operator's hands. By this arrangement the pitch of a screw like this of fourteen threads to the inch is reduced to one of twenty-eight, and the chance of jerking away the stone is proportionately lessened; and although the weight and length of the handle are increased, $I$ consider that no disadvantage, as it affords a firmer hand grasp. East Rudham. Alan Reeve Manby.

SocIeTy For the STUdy AND CURE OF IIJEBRIETY.The council of the Society had arranged for a Colonial and International Congress on Inebriety in London during the current month, but the General Election has made postponement desirable. The Congress will meet when Parliament sits. 


\section{THE LANCET.}

\section{LONDON: SATURDAY, JULY 10, 1886.}

THE College election, which is just over, will be held remarkable in times to come, because the Fellows, for the first time, have elected a general practitioner into the Council; and, secondly, because they have elected two provincial in face of some very eligible metropolitan Fellows. As regards Mr. SIBLEx's election, the Council may be fairly congratulated. Apart from the obvious desirability of the great mass of the profession-the general practitioners-being directly represented, Mr. SIBLEY cannot fail to be a persona grata to the Council. His well-known business aptitude and his liberal and tolerant views specially qualify him for his office, and will prove of eminent service in the Council chamber. We rejoice, however, not on these accounts alone, but because in this departure from routine we recognise a wise and advancing liberalism among the Fellows which augurs well for the future of the College. This liberalism is further illustrated in the simultaneous election of two provincial Fellows-a fact which las not previously occurred, as far as our memory serves us. At the present, therefore, the Council contains four members--a still too small, but a juster, proportion of provincial representation than has obtained at any previous period.

It was natural that Mr. Lund should head the list, and we are pleased to congratulate him, and on his majority over the next and following candidates. His votes, moreover, included only one plumper, Mr. SIBLEY having received three. To plump is usually a sign of personal over general considerations, of having zealous friends rather than special merit. It detracts from rather than adds to a candidate's success. Besides, it interferes with that appreciation of the esteem in which other candidates are held, which is as useful to the candidates themselves as it is interesting and serviceable to the roters at large. It may also be argued that Fellows are not competent to vote when they thus shirk the responsibility which a more orthodox division of their votes implies. Mr. BerKELEY Hill, Mr. Reginald Harrison, and Mr. Wrllett, with each ten plumpers, are no better or worse off than they would have been without them. On the whole, we must congratulate the Fellows, and the Members of the College also, on the result of the past election. The Council as at present constituted is more largely liberal and progressive than at any previous period; and we may look forward hopefully to the future for the realisation of those reforms which we have so often and so urgently advocated.

Following precedent, Mr. JoHN WooD would have become President; it is not surprising, however, that Mr. SAvory has been re-elected in acknowledgment of his valuable services, of the admirable manner in which he has discharged his presidential duties, and also of his position and eminence as a surgeon. We congratulate Mr. SAvoRY on being the first President on whom the honour of re-election to the presidential chair has been conferred since the name of the head of the College was changed from that of "Master." The only approach to a parallel case was in 1831, when Mr. RoBERT KEATE was chosen President after having occupied the chair part of the previous year in consequence of the death of his predecessor, Mr. R. C. HeAdington, before the completion of his term of office. Mr. WooD's turn is merely postponed for a year.

We can only express a hope that the new Council will use their best endeavours to bring about with all celerity an adjustment of the present differences subsisting between them and a large number of leading Fellows, and that they will also find means of enlisting the Members and their goodwill in the development and service of the College by timely and judicious concession in the directions sought by both classes of their constituents.

We have recently given account of Mr. W. H. PowER's report upon the prevalence of scarlatina among the consumers of milk from a farm at Hendon, and have expressed the conviction that the evidence which he adduced to show that a cow ailment caused the malady in man must be accepted as sufficient for this purpose. This evidence, it is true, was merely circumstantial, but the marked coincidence in the behaviour of the affections among the cows and among the consumers respectively placed it beyond reasonable doubt. that the one was responsible for the other.

We have now before us the report of Dr. KLEIN upon his own share of the investigation which was undertaken by the Medical Department of the Local Government Board, and again we find very strong corroboration of the conclusions: at which Mr. Power had arrived. It was Dr. KLEIN's duty to consider the subject from a different point of view than that taken by Mr. Power, and to test by such experiment as was possible the question whether the cow malady was a communicable disease, and whether in its results upon this animal there was indication of its being concerned in the production of scarlatina in man. The subject was not altogether a new one. In the year 1882 scarlet fever had been distributed with milk in the parishes of St. Giles and St. Pancras, and this milk had been received from a country farm where the condition of one of the cows was noted by Mr. Power, who conducted this inquiry. This cow had recently come into milk, and was evidently not in good health, as was shown by the fact that its hair had been shed in patches. In the absence of other evidence as to how the milk received infection, it was felt desirable that experiments should be made to show how far it was possible to inoculate cows with human scarlatina. It is unnecessary to refer more in detail to the lessons which were then learnt than to state, in the words of Dr. BUCHANAN, that it was found that a definite disease was producible in the cow by means of scarlatina infection, and that most readily when the cow was in milk.

A noticeable condition of the cows of the Hendon farm was the shedding in patches of their hair, resembling in this respect the cow which had attracted Mr. PowsR's attention in the previous investigation; but at Hendon were the further symptoms of vesication and ulceration of the teats and udder, supplying Dr. KLEIN with material for the prosecution of further inquiry. This virus was used for the inoculation of certain calves, with a result which clearly demon- 